\title{
Political, moral, and security challenges of space colonization
}

\section{ZIPAR Discussion Paper Series}

June 2018

Marko Kovic 


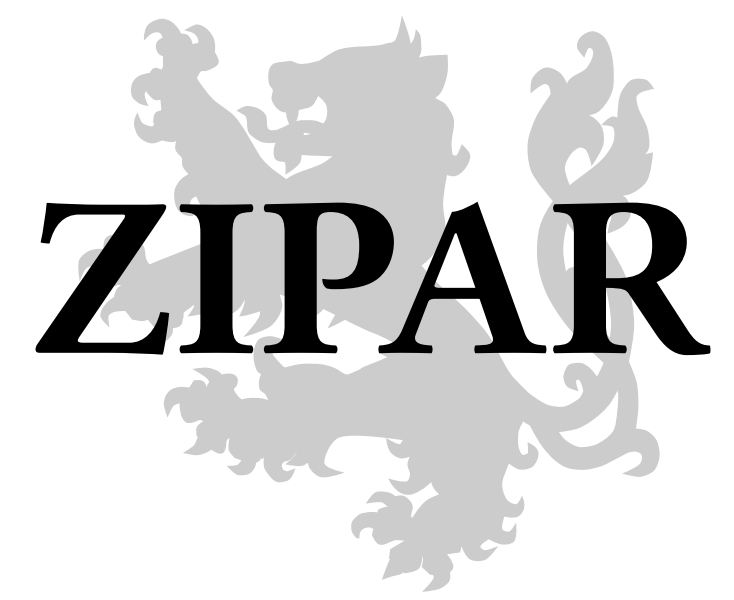

\section{About ZIPAR}

The Zurich Institute of Public Affairs Research is devoted to identifying and addressing the major challenges for humankind in the short-term, in the mediumterm, and in the long-term future. ZIPAR is an independent nonprofit think tank based in Zurich, Switzerland.

\section{Recommended citation}

Marko Kovic (2018): Political, moral, and security challenges of space colonization. ZIPAR Discussion Paper Series. Zurich, Switzerland.

\section{Copyright}

This document is licensed under a Creative Commons Attribution-NonCommercialNoDerivatives 4.0 International license. You can freely distribute this document and reference it in other works. For any questions about copyright, feel free to contact the authors (marko.kovic@zipar.org; adrian.rauchfleisch@zipar.org; christian.caspar@zipar.org). 


\begin{abstract}
Space colonization, the goal of establishing permanent and self-sustaining human habitats beyond Earth, is not only a technological challenge: Colonizing space will confront humankind with a set of political, moral, and security challenges. If the outcomes of those challenges are negative, space colonization will either fail completely (political challenges), or we will commit potentially immense moral damage (moral challenges), or we will expose humankind to enormous security risks (security challenges). In order to minimize these risks, we need to start crafting policy blueprints today that are aimed at steering space colonization in a desirable direction
\end{abstract}




\section{Contents}

1 Introduction 5

$1.1 \quad$ Preliminaries 1: What do we mean by space colonization? . . . 5

1.2 Preliminaries 2: Why space colonization? . . . . . . . . . 6

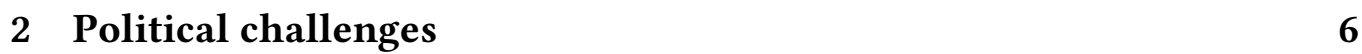

2.1 Who is allowed to colonize? . . . . . . . . . . . 7

2.2 Governance of colonies . . . . . . . . . . . . . . . 8

2.3 Secession and independence . . . . . . . . . . . . . . . . 9

2.4 Pan-human governance $\ldots \ldots \ldots \ldots 11$

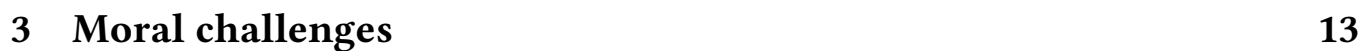

3.1 Population ethics $\ldots \ldots \ldots \ldots \ldots$

3.2 Inequality $\ldots \ldots \ldots \ldots \ldots \ldots \ldots$

3.3 Extraterrestrial life $\ldots \ldots \ldots \ldots \ldots \ldots$

3.4 Cosmic suffering . . . . . . . . . . . . . . . 18

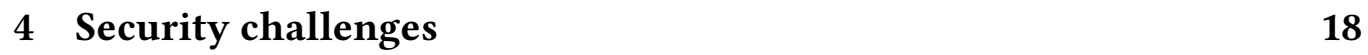

4.1 Inter-colonial war . . . . . . . . . . . . . . . . . . . 19

4.2 Extraterrestrial (existential) risks . . . . . . . . . . . . 20

5 Conclusion: Do the benefits outweigh the risks?

5.1 Policy implications $\ldots \ldots \ldots \ldots 21$ 


\section{Introduction}

Many great science fiction stories are based on an outrageous, yet not completely unrealistic idea: Humans might one day spread beyond Earth. Probably ever since our understanding of the cosmos has become (proto-)scientific, humans have been dreaming of conquering space, the next great frontier. From a technological point of view, we have already made great strides towards that goal: We have developed the means for routinely visiting near-Earth orbit and even the Moon in person, and unmanned spacecraft have just about reached the border of our solar system [1].

Of course, there are still many technological hurdles to overcome in the pursuit of space colonization capabilities, such as mitigating the negative health effects of prolonged space travel [2] or the development of propulsion technology beyond today's chemical rockets [3]. But the technological challenges we are facing seem to be fundamentally solvable: Given enough time and effort, we should be able to develop the necessary technology to venture beyond Earth. That is why space colonization is not merely a science fiction trope, but rather an ideal of human progress, ingenuity, and optimism, as expressed most eloquently by the astrophysicist Carl Sagan in his famous book «Pale Blue Dot» [4].

However, space colonization is not merely a technological undertaking. Without sufficiently advanced technology, we will not be able to colonize space. But technology itself does not solve some other challenges and problems that arise with space colonization. After all, once we can colonize space, we will be faced with the questions of how we should do it and what could go wrong. More specifically, a set of political, moral, and security challenges arise with the prospect of space colonization. Even though space colonization is some way off, it is prudent to address the non-technological challenges of space colonization today.

\subsection{Preliminaries 1: What do we mean by space coloniza- tion?}

The term «space colonization» is somewhat unfortunate, because it is reminiscent of colonialism. Colonialism was the (predominantly European) practice of settling in and taking political control of foreign territories, including the local populations in those territories [5]. European Colonialism did not have one single goal, but it was usually means to both economic and cultural ends.

Space colonization, of course, does not refer to the continuation of colonialism in space. Usually, space colonization is a shorthand term for permanent and self-sufficient human habitats beyond Earth. Describing the creation of human habitats beyond Earth as space colonization is actually inaccurate, because the goals of historical colonies are not the same as the goals of space colonies. Human 
habitats beyond Earth might benefit humans on Earth, but the main goal of habitats beyond Earth is not subjugation, but exploration. In this article, I use the term space colonization for the sake of convenience, even though the term is imprecise.

\subsection{Preliminaries 2: Why space colonization?}

In discussions surrounding space colonization, the belief that we should engage in space colonization is often treated as an implicit premise. But why, exactly, should we engage in space colonization?

One answer to this question is pragmatic in nature: Under no reasonable set of assumptions will humankind not engage in space colonization activities, so there is no point in even discussing whether we should do so or not. We should instead focus on getting it right. Even though this pragmatic argument makes a fair amount of sense, it is essentially just a recursive justification and as such not really a satisfying answer as to why space colonization should be desirable.

A second answer is motivational in nature: We humans are natural explorers, and space is the next great frontier that we want to explore. Having such grand collective goals gives humankind some kind of sense of instrumental purpose; we can strive for and contribute to a great goal for humankind. This argument of instrumental purpose might sound somewhat vague and emotional, but it is nonetheless important. In general, people tend to derive motivation from setting goals [6]. Space colonization is not a goal that any one individual can achieve, but it can serve as a kind of meta-goal that gives humankind as a whole a sense of purpose and direction.

A third answer is risk-related in nature: Establishing permanent and selfsufficient habitats beyond Earth is a risk-mitigation strategy in case something goes wrong on Earth. More specifically, space colonization is a generalized strategy for mitigating existential risks. Existential risks are risks that endanger humankind as a whole [7] , and they are growing due to our technological development. The premise of this view on space colonization, obviously, is the belief that humankind should exist rather than not exist in the future. That moral premise might seem intuitively reasonable, but it is not necessarily without its problems, as is explored below in the context of moral challenges of space colonization.

\section{Political challenges}

Space colonization is perhaps not obviously, but fundamentally political in nature: Colonizing space is either contingent or creates the necessity for collectively 
binding decisions and rules. The political challenges of space colonization roughly follow a potential timeline from today into the long-term future of a colonized space. First, and immediately, there is the question of who is actually allowed to engage in space colonization. Second, we will need to address basic governance principles of preliminary colonies in the medium-term future. Third, in the medium- to long-term future, we will have to adequately deal with colonies that might wish to secede and become independent. Fourth, in the long-term future, we will be faced with the question of pan-human governance between independent human habitats in our Solar System and beyond should look like.

\subsection{Who is allowed to colonize?}

Imagine two disparate colonization attempts of Mars. First, NASA decides to establish a colony on Mars, for research and exploration purposes. Second, the European Space Agency decides to do much the same. Which of these two colonization projects is allowed? Both are. As are any number of other colonization efforts: Any individual or organization or country is allowed to engage in space colonization, because space is legally regarded as belonging to all of humankind.

The foundational legal framework for space colonization is the Outer Space Treaty from 1967 [8, 9]. One of the main goals of the Outer Space Treaty is to promote peaceful exploration and use of space that benefits all of humankind. The treaty does not generally restrict activities in space, with the exceptions of procuring weapons of mass destruction into space and appropriating celestial bodies unilaterally. The basic idea of the Outer Space Treaty is therefore that space belongs to all of humankind and that it should be explored and used for peaceful purposes only.

The notion that space should belong to all of humankind is appealing, because it implies a peaceful and cooperative future. However, the current legal situation is also creating uncertainties. Consider, for example, a private mining company that is pondering establishing colonies on the Moon and on Mars in order to extract minerals and metals in order to bring them back to Earth. The company does not want to lay claim neither to the Moon nor to Mars, so it is not in outright violation of the Outer Space Treaty. However, under the Outer Space Treaty, it is not clear whether the mining company would actually be allowed to mine on the Moon and on Mars for business purposes [10]. The Outer Space Treaty prevents any actor from appropriating any celestial body, but it is not clear whether the hypothetical mining company would be engaging in a form of appropriation or in a permissible activity.

The logic of colonization activity in space is somewhat similar to the logic of activity in international waters under maritime law [11]. Individuals and organizations who are present in international waters generally have to obey the 
laws of their country of origin. That principle also applies to space colonization, and it has the benefit of preventing a state of complete lawlessness. The drawback of this principle is that individual countries might opt to act unilaterally in devising laws that regulate space colonization efforts in ways that are aligned with their interests, but not necessarily with the interests of all of humankind. Unilateralism might ultimately defeat the purpose of common frameworks such as the Outer Space Treaty and exacerbate problems such as the tragedy of the commons [12] (the problem of overusing of a shared system of resources that is ultimately detrimental to everyone). The tragedy of the commons is already a problem of current space exploration, for example in the context of space debris [13]. Unilateral developments such as a proposed 2017 bill in the United States that is intended as a stimulus for commercial space exploration and colonization [14] demonstrate that unilateral decision-making in matters of space colonization is already starting to become a reality. However, and on the other hand, a strict interpretation of the Outer Space Treaty is probably not a solution to the looming coordination problems. Interpreting and enforcing the Outer Space Treaty in a strict and restrictive manner might have a disincentivizing, negative effect on both public as well as private entrepreneurial colonization efforts.

Coordinated international work on space-related regulatory rules and frameworks has made little progress in recent years [15]. No international consensus on a modern approach to space colonization and colonization-related problems is on the horizon.

\subsection{Governance of colonies}

Let us imagine that the problem of who is allowed to colonize is solved one way or another, and two preliminary colonies are established; one on the Moon, and another one on Mars. These hypothetical colonies are not yet fully independent and self-sustaining, but rather permanently manned outposts of humankind. Let us further imagine that these two colonies have been established by different actors: The Moon colony has been created by a private mining company, whereas the Mars colony is a joint international project of public space agencies, much like the International Space Station [16]. What, exactly, should governance in these two colonies look like?

At first, it might seem that the answer to the question of governance is simple. The Moon colony simply has to comply with company policy and with the laws of the country to which the company belongs. The Mars colony could follow the example of the International Space Station, where crew members behave in accordance with the laws of their countries of origin and conduct their missions according to the overall joint mission agreements [17]. Unfortunately, existing governance solutions are probably not adequate even for preliminary 
space colonies such as our two imaginary examples.

The longest extraterrestrial human deployment in space so far was conducted in low-Earth orbit, on the International Space Station, and lasted slightly longer than 11 months. The mission consisted of two permanent and six non-permanent people [18]. Very limited deployments to space (as all have been so far) can operate with existing simple governance principles. Slightly more complex deployments into space in the context of preliminary colonies, however, might require more thorough and more autonomous governance.

Even preliminary colonies, such as our fictional ones one the Moon and on Mars, are more complex than current space missions. Such colonies would necessarily be semi-autonomous, at the least, because increasing the complexity of missions in space means that the number as well as the nature of decisions that have to be made in situ change. In part, that is a purely logistical problem: If it takes several days (in the case of the Moon) or several months (in the case of Mars) to physically reach the preliminary colonies, the colonies must make more decisions on their own. Even if a preliminary colony operates fully under the laws of the country or countries of its origin, enacting those laws cannot easily be relegated to Earth. For example, criminal behavior will need to be dealt with in the colonies themselves in some way. The best model for early space colony governance is difficult to model. Simulated preliminary space colonies, such as the HI-SEAS habitat on Hawaii [19], will produce valuable data on governance problems and dynamics that emerge in such situations.

As early preliminary colonies grow and become more self-sufficient, the governance question will become more prominent. The relationship between governance problems and colony complexity is probably non-linear: Even colonies that are modest in size and number will produce governance problems and requirements about as large as the ones we experience today in society. Having rules for making decisions is universally necessary whenever groups of people have to make decisions; that will not change for groups of people residing in habitats beyond Earth.

\subsection{Secession and independence}

Let us imagine a space colony in our solar system that is a truly self-sufficient habitat beyond Earth where hundreds of thousands or even millions of people live, potentially permanently. The Moon and Mars are unlikely candidates for such colonies because of the detrimental health effects of their low gravities. For the sake of argument, let us assume that our imaginary advanced colony is located on Venus after it has been successfully terraformed [20]. The Venus colony has found viable ways of local governance, a form of pluralism among the colonizers in combination with a light planetary governing body [21], and it is prospering 
and enjoying a peaceful and mutually beneficial relationship with Earth. At some point, however, the inhabitants of Venus decide that they want more than just semi-autonomous governance: They want full autonomy and independence. They want to secede from Earth. What then?

The general prospect of colonial secession might seem like speculative science fiction, but there is nothing inherently implausible about it. After all, the history of Earth-bound colonization has amply demonstrated that colonies might yearn for independence at some point (Even though, as remarked in the preliminaries, space colonization does not mean quite the same as historical European colonialism.). Colonial secession is probably not a short- or medium-term prospect, but it is likely to be one of the main political challenges if we reach advanced levels of space colonization, not least because it is an issue for which we have no precedent. In principle, there is no strong a priori argument against independent human colonies: If we believe in the concept of popular sovereignty (the foundation of modern notions of political legitimacy), then any space colony should be allowed to become independent. In addition, secession might, in the sense of liberation, serve as an epistemic, moral, and cultural accelerator of the space colonies and of humankind as a whole [22]. However, even though the general idea of future independent colonies might not be contestable in principle, the actual process of peaceful secession is not at all clear.

There are at least three challenging aspects to colonial secession: The initial requirements, the secession procedure, and the target political system. The initial requirements are the requirements that would have to be met in order for a secession to take place. The requirements could consist of rules regarding the nature of the colony in question (for example, only colonies that are operated by public actors such as countries on Earth and that fulfill some size criteria might be eligible for independence) and of petitioning rules (for example, two thirds of the colony inhabitants might have to agree to the secession). The initial requirements are probably the least difficult part of colonial secession.

The actual secession procedure is more challenging. Ideally, the secession procedure would be a simple checklist: If a colony fulfills all the requirements for secession, independence would be granted. Let us assume that our fictional Venus colony fulfills all requirements and is eligible for secession. Would we, the citizens and governments of Earth, be willing to grant independence to Venus? Ideally, yes, but in all likelihood, Earth governments and countries will be reluctant to give up their political power over the parts of the Venus colony that belong to them. It might be necessary to develop a robust process for determining independence. That process could be a democratic vote. For example, if two thirds of the members of the United Nations accept the secession request, independence is granted. But would that actually be fair? It is easy to imagine scenarios in which large and powerful countries might coerce smaller countries to submit to their 
preferred vote, thus rejecting independence of the Venus colony. A better decision mechanism might be that colonial secession is automatically granted when the requirements are met unless a majority of UN members actively petitions against independence, thus triggering a process of closer scrutiny and decision-making process. There is precedent for a similar kind of arrangement: Countries that are members in the World Trade Organization WTO can put forward complaints about other member countries, and those complaints are then assessed within a dispute settlement procedure [23].

The aspect of the target political system is probably the greatest challenge of colonial secession. Imagine, for example, that our fictional Venus colony is predominantly a project of the Chinese government. The Venus secessionists want to secede because they have adopted radical Maoism and want to establish a communist dictatorship. Would that outcome be acceptable? If we were to implement the idea of popular sovereignty in very simplistic terms, then yes, whatever the colony population wishes for would be acceptable. If we think about this question in a slightly more profound manner, it is obvious that the answer is not so simple: If the basis of colonial secession is the notion of popular sovereignty, then, one way or another, we are already operating within a democratic framework. But it is not at all clear whether all governments on Earth would agree that the target political system of independent colonies should be a democratic one. From a rational point of view, it is desirable that independent colonies be democratic and implement principles such the rule of law, human rights, and democratic elections, but it is doubtful that non-democratic countries on Earth would require independent colonies to be democratic, since such a rule would directly undermine them. In our fictional example, China would hardly press for the Venus colony to be a democratic system when China itself is an anti-democratic country (Assuming that China continues to be anti-democratic in the future.).

\subsection{Pan-human governance}

Let us assume that the problems of secession have been overcome in the future, and humankind has become what we might call a phase II colonizing civilization: We have established permanent habitats in our Solar System and beyond. We have, in other words, mastered intersolar travel and colonization (but not yet the intergalactic kind, which we might call phase III colonization) and humankind is still connected culturally, genetically, and physically. Humankind has spread across many planets, moons, and space stations, many of which are independent entities, and our technological advances allow us to travel between different habitats in reasonably short time spans. One important aspect of such a scenario is not self-evident, however: The manner in which different independent habitats would interact with each other. 
There are three general models of potential future pan-human governance:

- Model 0: No formalized governance (bilateralism).

- Model 1: Weak federation.

- Model 2: Strong federation.

Model 0 is the absence of any kind of formal pan-human governance structure. In such a model, independent and autonomous habitats do as they wish and they entertain strictly bilateral relationships with each other. Model 0 would be the easiest to implement, but it has major drawbacks. For example, model 0 might actually be detrimental to successful space colonization, because well thought-out principles (such as the yet to be defined secession rules) would almost certainly not be universally applied, potentially halting fruitful colonization dynamics. Thankfully, it is very improbable that future habitats of humankind (including Earth) would opt for model 0, because such a system would almost certainly result in great transaction costs that make cooperation very difficult and that thus result in worse outcomes for all parties involved. This realization is perhaps the main reason why we have a dense network of intergovernmental organizations today [24, 25]: Countries agree to play by rules that are not always in their immediate self-interest because they know that doing so makes cooperation easier and more predictable. Pan-human governance will therefore almost certainly take the form of either model 1 or model 2.

Model 1 is the model of a pan-human federation that consists of all independent habitats on a habitat-level basis. For example, Earth would be a member of such a federation, not individual countries on Earth. A model 1 pan-human federation would be weak in that its goal is creating binding pan-human policy, but it without the possibility of enforcing its policy with strong sanctions. More specifically, a model 1 pan-human federation would be able to exercise economic sanctions, but not military ones.

A model 2 pan-human federation, in contrast, would be able to enforce policy both through economic and military sanctions. This means that, from a practical point of view, a model 2 pan-human federation would wield at least as much decision-making and sanctioning power as the United Nations does in today's context of international politics [26], including the possibility of military interventions in cases of noncompliance with some foundational policy requirements.

Regardless of whether pan-human governance gravitates towards a model 1 or a model 2 federation, crafting the actual policy contents of a pan-human federation will be difficult. The United Nations, for example, is not the result of a purely philosophical exercise in how best to reduce transaction costs - the United Nations was created in the immediate aftermath of World War II with the 
express goal of preventing such devastating conflicts in the future. Hopefully, reason alone will suffice to create the policy basis for a pan-human federation, without the need for some catastrophic trigger event. The general principle of equality between human habitats might be beneficial in this pursuit: If all future independent colonies accept that there is a need for pan-human governance and that they need to formulate initial policy as equal partners, then hope in a pragmatic initial solution does not seem misplaced.

\section{Moral challenges}

Space colonization creates not only political, but also moral challenges, and it does so in two ways. Space colonization can potentially drastically increase some existing moral concerns and problems, such as issues relating to population ethics and to inequality. Space colonization can also face us with entirely new moral challenges, such as our behavior towards extraterrestrial life and the risk that we might (inadvertently) spread tremendous suffering through the universe.

\subsection{Population ethics, or: The repugnant conclusion on steroids?}

If humankind succeeds in colonizing space, the absolute number of people in existence will probably be greater than if space colonization did not take place. Even if technological innovations such as rejuvenation [27] should result in a decrease in reproductive activity, the total human population is more likely to increase than to stagnate or decrease. An increase in the total population is not, in and of itself, problematic. However, a potentially drastic increase of the human population in the wake of space colonization could make a specific problem of population ethics very salient: The mere addition paradox, or, as it is better known, the repugnant conclusion [28].

The repugnant conclusion is an apparent ethical paradox. On the one hand, we usually have a preference for as much happiness as possible (or as little suffering as possible) in a population. On the other hand, a lower average happiness (or level of suffering) also seems morally acceptable if it results from a population increase. In order to demonstrate this point, let us return to our fictional Venus colony. Let us assume that there are around 1 billion people on Venus, in addition to the 8 billion on Earth. Life on Venus is almost identical to life on Earth in terms of happiness and suffering. There is only one slight difference: Due to the composition of the terraformed atmosphere on Venus, people who suffer from asthma (an inflammatory disease of the airways) have to endure slightly more unpleasant asthma attacks. On average, this means that life for the inhabitants of Venus is $1 \%$ more unpleasant than life for inhabitants of Earth. The conclusion in 
this example is that, slight though the difference is, the existence of the 1 billion people on Venus results in an lower average level of happiness and in a greater average level of suffering for humankind. Would it be preferable that the 1 billion people on Venus did not exist? Or is the existence of the 1 billion people on Venus justified, because the total amount of happiness is greater than if they did not exist?

Most people will intuitively answer that the existence of the Venusians is morally justifiable, perhaps mainly because the difference in welfare between Earth and Venus is so small. Unfortunately, the general problem in this fictional comparison of Earth an Venus holds for situations in which the differences in welfare are enormous. That is what is repugnant about the repugnant conclusion: Even in situations in which vast numbers of people live in abhorrent misery and suffering, the total amount of happiness can increase. In theory, even 100 billion slaves who work on space colonies only to serve their Earth masters would result in a net increase of happiness, even though the average level of happiness would decrease tremendously compared to today. Is there a solution to the repugnant conclusion in the context of space colonization? A useful moral guideline could be to adopt facets of anti-natalist moral philosophy [29]. Anti-natalism is a philosophical position that shifts the moral calculus of happiness and suffering: Even though we experience a lot of happiness in life, the suffering we experience is always at least as great. The conclusion from this adjusted calculus is that, under the best of circumstances, the overall welfare of a human life is neutral (happiness and suffering are in balance), but it is almost always negative (suffering outweighs happiness).

Implementing anti-natalism directly into the moral framework of space colonization cannot work, since direct anti-natalism is a rather obvious argument against space colonization. However, implementing a part of the anti-natalist argument into the moral framework of space colonization could be a pragmatic solution. This could be done by adopting the moral guideline that additional lives created in the course of space colonization are justified when and only when those lives enjoy at least the average level of welfare that existing lives enjoy. Such a guideline would be a strong moral imperative to not colonize space merely for the sake of colonization, but in order to improve the average welfare across humankind.

\subsection{Inequality, or: The Matthew effect on steroids?}

Inequality is a basic fact of life. Not all people are born into the same contexts and with the same biological faculties, resulting in vastly different outlooks in their lives, regardless of individual motivation and discipline. In addition, inequalities in life have cumulative effects [30] that result in a kind of Matthew effect («For to 
every one who has will more be given»). Mitigating inequalities is generally one of the top priorities of modern governments, as is evidenced by the existence of some form of social security net in virtually all countries..

The challenge of cumulative inequality could grow over the course of space colonization. Those individuals, families, organizations, and countries who enjoy relatively greater wealth and opportunities (which in itself is not morally bad) might enjoy greater access to opportunities thanks to their better starting conditions. A very plain example could be a wealthy family that can afford to invest in the colonization of a hitherto unoccupied planet, which might result in even greater wealth accumulation within that family. That is, again, not a bad thing in and of itself, but exacerbated inequality in the context of space colonization should be a concern. Large-scale cumulative inequality might seem like an abstract and unrealistic challenge, but we know from ample historical evidence that these kinds of cumulative wealth inequalities can and do occur [31]. Given our prior experience with addressing inequality and its negative side-effects, we can be reasonably confident that we will be able to continue addressing inequality in the space colonization era. Inequality is likely to remain a priority.

\subsection{Extraterrestrial life}

The scientific understanding of the origins of humankind and of life on Earth thus far paints a clear picture: We are the «products» of biological evolution, just as all other life forms on Earth. Furthermore, we know that life can come into existence where there was no life before, through so-called abiogenetic mechanisms. These basic facts lead to a clear conclusion: It is very improbable that life on Earth is a once-in-a-universe event; it is highly probable that life has come into existence elsewhere in the universe as well. We do not know whether extraterrestrial life currently exists, and whether there is any extraterrestrial life in our vicinity (as far as we know, there is none in our Solar System). In theory, our galaxy might be full of life and even highly intelligent and technologically advanced life, but, as the famous Fermi paradox posits [32], there is no trace of any extraterrestrial intelligence. Be that as it may, it is possible that there is extraterrestrial life beyond Earth, and it is possible that we will come into contact with extraterrestrial life due to colonization activity. What should our moral attitude towards extraterrestrial life look like?

The moral issue of our attitudes towards extraterrestrial life can be divided into three classes of problems, according to the type of life we are dealing with:

1. Primitive non-sentient life.

2. Primitive sentient life. 


\section{Non-primitive sentient life.}

Primitive non-sentient life are life forms that resemble microbial life forms on Earth, such as bacteria. Extraterrestrial microbial life can be of great instrumental value, specifically to humans, but also in a more general sense. That is a strong argument in favor of studying and preserving extraterrestrial microbial life [33]; we should not go out of our way to destroy microbial life, because that life might be very useful. The main moral issue about primitive non-sentient life, however, is not the question of instrumental value, but rather the question of intrinsic value: Is there a moral obligation for humans not to manipulate or even end extraterrestrial microbial life forms? This problem is, in all likelihood, the most pressing moral issue about extraterrestrial life and space colonization and one that deserves greater practical attention [34]. A common argument in favor of the intrinsic value position is that of conation or goal-orientedness [35, 36]: Because even microbial life forms act vaguely rational (they have goals and behave so as to achieve their goals), their existence has some intrinsic value. The problem with this moral argument is that it can easily lead to the conclusion of strong conservationism, whereby any habitable planet or moon should remain uncolonized, lest we interfere with microbes that we might have failed to detect [37]. In addition, if we accept a strong version of the intrinsic value argument, we already have immense moral problems: On Earth, we do not particularly care for any microbial life form on intrinsic grounds, and we even actively fight some of them.

Primitive sentient life are life forms that are not as intelligent as humans, but that are sentient, in the sense of being able to experience positive or negative affective states. Even though sentience is not a perfectly precise concept [38], and even though we lack the means for truly assessing qualia (subjective experiences) of life forms other than humans [39], it is almost certain that we humans are not the only life form capable of experiencing pain and pain-related suffering and that many animals on our planet are sentient as well [40]. Sentient extraterrestrial life forms require a different moral stance than non-sentient life forms. Imagine, for example, that two human space ship are about to land on an exoplanet. As the space ships are landing, the exhaust from their engines heat up the ground. Space ship A is landing on a nest of insect-like non-sentient life forms, frying them alive in the process. Space ship B is landing on a herd of bunny-like sentient creatures, frying them alive in the process. Both outcomes are unfortunate, but undoubtedly, killing the sentient bunny-like creatures must be morally worse than killing the non-sentient insect-like creatures, because the bunnies experienced enormous pain while they were being killed. Our moral stance towards sentient primitive extraterrestrial life will have to take sentience into account. Avoiding suffering in sentient extraterrestrial life should be a universal rule of space colonization. 
Somewhat obviously, such a rule would also prohibit treating sentient extraterrestrial life forms as food (But it is highly improbable that humans would have to routinely rely on extraterrestrial sentient life forms as sources of nutrition, even though we would be technologically advanced enough to engage in intersolar space colonization. We are in the process of overcoming traditional agriculture today [41]; reverting to traditional agriculture on future extrasolar colonies would amount to an extraordinarily improbable and inefficient anachronism.).

Non-primitive sentient life are life forms that are sentient and possess a general intelligence at least as great as our own (It is possible that highly intelligent life forms might be non-sentient, but at least on Earth, sentience seems to correlate with intelligence.). The moral challenge of this type of extraterrestrial life is the same as with primitive sentient life, and there are additional moral problems to consider. If there are intelligent life forms beyond Earth, their levels of technological development will have great variance; some life forms will be intelligent, but not yet developed, whereas others will be intelligent and much more technologically advanced than we are. Intelligent life forms that are less technologically developed than we are present us with a moral problem: Should we interact with such civilizations and try to help them develop faster and overcome problems? This moral problem has perhaps most famously been explored in the television show Star Trek with its «Prime Directive»: The fictional United Federation of Planets is never to interfere with a technologically undeveloped civilization in order to avoid doing damage (Alas, the protagonists of Star Trek end up violating the Prime Directive time and again; doing so makes for a good story.). More generally, the problem of non-interference can be described as a reversed Zoo hypothesis [42], whereby it is not extraterrestrial civilizations treating Earth like a conservation project, but us humans pondering whether we should treat extraterrestrial civilizations as conservation projects. A strong argument in favor of non-interference is the risk of both causing bad outcomes, both in the shortas well as in the long-term. Interacting with less developed civilizations might inadvertently do more harm than good, and it might steer the affected civilizations away from a path to development that might be beneficial to humankind in the long run. On the other hand, however, not investing a small amount of resources to greatly improve lives and reduce suffering seems morally dubious. If an extraterrestrial civilization that is going through a historical era similar to our Middle Ages is confronted with some catastrophic disease like our Black Death pandemic, not helping that civilization fight that pandemic seems cruel; not least because the cost for helping that civilization would almost certainly be trivially low. 


\subsection{Cosmic suffering}

Imagine that humankind has successfully mastered phase II colonization (colonization beyond our Solar System). All the problems described in the previous sections and subsections have long been successfully solved, and humankind is progressing steadily and peacefully. Then, something happens. At some point and for some reason, future humans decide that they do not want to merely engage in space colonization, but to do more: Actively seed the universe with (non-human) life [43]. Given the technological development of future humankind, it is relatively easy to send out non-sentient primitive life forms across the galaxy. Unfortunately, something horrible happens: The primitive microbial life-forms sent out into the cosmos mutate into aggressive bacteria that attack any life form they encounter, including sentient life - and in doing so, they cause tremendous pain and agony in the organisms they attack. The benevolent idea of spreading life has quickly turned into unimaginable suffering of trillions of sentient beings across the galaxy. Colonizing humans have thus created suffering on a cosmic, or astronomical, scale [44].

Cosmic suffering is the risk of creating suffering on a scale that is either not possible or not as probable without space colonization. There are many potential scenarios in which successful space colonization results in cosmic suffering. For example, the general problem of the repugnant conclusion discussed further above can also be regarded as an example of this class of risks. Cosmic suffering is a severe problem because it is contingent on, or at least made more likely by, successful space colonization. The conceptually challenging aspect of cosmic suffering is the correlation of cosmic suffering with the degree of space colonization: The greater the level of space colonization, the greater the risks of cosmic suffering become. This is the opposite of the relationship between space colonization and existential risks: The greater the level of space colonization, the lower existential risks become - this is one of the main motivations for space colonization, after all. In other words, successful space colonization decreases the probability that something goes wrong for humankind in terms of existential risks, but it increases the probability that something goes wrong in terms of suffering for the whole universe.

\section{Security challenges}

In the above discussions of political and moral challenges, it is presumed that the problems and challenges that arise do so in a generally peaceful system of colonization. However, peace in the sense of a lack of armed conflict is not guaranteed with space colonization. On the contrary: Space colonization might 
produce new kinds of security challenges.

\subsection{Inter-colonial war}

Violence and war have been decreasing over the course of our civilization's history [45, 46, 47]. The decrease in violent armed conflict has coincided with an increase in cultural, political, and economic interconnectedness. Even though major armed conflicts are not yet a thing of the past [48], humankind will probably continue on its current trajectory of peace. With space colonization, however, the trend of growing closer together might reverse because of increasing fragmentation, and with that reversal, peaceful cooperation might again give way to armed conflict.

Some amount of human fragmentation due to space colonization is almost inevitable. One of the strongest biases we humans have is the intergroup bias [49]: We tend to separate people into ingroups and outgroups, and we generally favor our own ingroup over any outgroup. Our ingroup favoritism is often the source of collective identity: We identify with our home city and think it is better than other cities; we identify with our favorite football team and think it is better than other teams; we identify with our country of origin and think it is better than other countries. In a future in which humans have successfully mastered type I colonization (colonization within our Solar System) and perhaps even type II colonization (intersolar colonization), belonging to one habitat rather than another will almost certainly also be a source of collective identity. Humans born and raised on Venus would probably have more positive general attitudes towards Venus than towards Earth. That is not a problem in and of itself, but it can become a problem: If humankind is very successful at space colonization and manages to establish colonies across the galaxy, the ingroup dynamics within colonies and regions of colonies might grow so much that the perceived benefits of armed conflict increase, and the perceived costs decrease. In part, this might be due to the infrahumanization (or dehumanization) bias [50]: Our intergroup bias can have the effect of perceiving members of the outgroup as less human than members of our own ingroup.

The problem of intergroup bias and armed conflict could be compounded by real biological differences in the long-term future. In the long term, different colonies of humans might adopt different stances on human enhancement technology and embrace different kinds of enhancement technologies. These differential paths of human enhancement might result in technology-induced quasi-speciation, whereby different strands of humans have increasingly distinct biological traits. The ultimate result of such a development might be a strong fragmentation of humankind and an increasing arms race in order to defend against the outgroup of all the (former) humans that are different from the ingroup (former) humans [51]. 


\subsection{Extraterrestrial (existential) risks}

Space colonization will increase the probability of discovering and coming into contact with extraterrestrial intelligence, either biological or artificial (in the sense of hypothetical advanced artificial general intelligence [52]). That prospect poses some moral challenges, as argued in subsection 3.3. However, it might also pose a security challenge if an extraterrestrial intelligence more technologically advanced than humankind has goals and preferences that go against the goals and preferences of humankind.

In general, there are three categories of attitudes an extraterrestrial intelligence can have towards humankind [53]. First, an extraterrestrial intelligence can be benevolent. A benevolent extraterrestrial intelligence is one that would change its goals and preferences upon learning of humankind. Humankind is a benevolent intelligence: If we, for example, came into contact with an extraterrestrial civilization, we would obviously take the goals and preferences of that civilization into account and update our own goals and preferences, since we are morally advanced enough to do so.

Second, an extraterrestrial intelligence can be apathetic. An apathetic extraterrestrial intelligence is one that does not at all change its goals and preferences upon learning of humankind. An apathetic intelligence would neither try to accommodate humankind, nor would it react in some non-friendly way. It would not care at all. The attitude of an apathetic intelligence is similar to the attitude we humans have when it comes to some random microbial life form on Earth: We might understand that that life form exists, but we do not care either way.

Third, an extraterrestrial intelligence can be hostile. Hostility in a general sense means that an intelligence reacts to learning of humankind by regarding its own goals and preferences as categorically more important than humankind's. A hostile extraterrestrial intelligence is not necessarily a security threat to humankind; hostility in this context does not mean hostility in the Hollywood kind but hostility in the sense of active disregard of humankind's goals and preferences. That, however, might still represent a tremendous security risk. For example, a hostile intelligence might prefer humankind not to exist because our mere existence is perceived as a slight discomfort to the extraterrestrial intelligence. Hostile extraterrestrial intelligence thus represents a form of existential risk.

\section{Conclusion: Do the benefits of space coloniza- tion outweigh the risks?}

Space colonization represents numerous political, moral, and security challenges. In view of the different challenges and problems that arise with space colonization, 
we need to ask: Is space colonization actually worth it, given that so much can go so wrong?

In general, the assessment of the benefits and risks of space colonization needs to take into account the difference between direct logical consequences and probabilistic outcomes. The challenges outlined in this paper are all consequences of space colonization, but the outcomes of those consequences are not deterministic, but probabilistic: Things might go wrong, but they might also go as desired. The strongest argument in favor of space colonization, the reduction of existential risks, can also be regarded as probabilistic: The probability that humankind can survive in the long-term if we do not engage in space colonization is 0 (The probability that some existential risks will lead to the end of humankind approaches 1 in the long run.). In other words: Humankind will almost certainly perish if we do not engage in space colonization, but there is some probability that space colonization might result in (very) bad outcomes. A pragmatic course of action for this dilemma seems to be to start working today on making sure the future outcomes of space colonization are as positive as possible.

\subsection{Policy implications}

The numerous challenges of space colonization outlined in this paper need to be addressed through problem-oriented policy. Space colonization is the kind of problem (or collection of problems) that can benefit greatly from policy aimed at realizing the best possible outcomes [54]. Space colonization policy, however, does currently not feature high on the political agenda, neither in individual countries nor on the international political stage. Rather than continue being inactive in this area, national governments should regard the current situation as a window of opportunity: Our current stage of technological development is a uniquely opportune moment for crafting policy that addresses political, moral, and security challenges of space colonization before we actually engage in space colonization. Policy aimed at making the best outcomes of space colonization more probable is best created before humankind engages in large-scale colonization activities - better to anticipate and steer space colonization in the best possible direction than to engage in damage control after the fact.

Formal international work on space colonization policy is likely to remain difficult and protracted in the coming years. A more promising venue might be to begin informal work on policy proposals that might serve as blueprints and nudges for international policy making. To that end, the creation of one or several national as well as international consortia of public, private, and third sector organizations and actors is desirable (Some of the major actors of space exploration today are private companies, and space colonization policy should be crafted in concert with, not in opposition to private companies.). National 
consortia would have the advantage of being relatively easy to set up and maintain, but the impact of national consortia would likely be limited. In contrast, forming and maintaining an international consortium would be more difficult, but its impact would be greater.

Practical work on space colonization policy should begin as soon as possible. Even though preliminary colonies beyond Earth will require at least several decades to realize given current trends of technological development, sudden and unexpected technological breakthroughs might make space colonization much more feasible. Humankind needs to be ready either way. 


\section{References}

[1] Richard A. Kerr. "It's Official-Voyager Has Left the Solar System". In: Science 341.6151 (2013), pp. 1158-1159. DOI: $10.1126 /$ science. 341 .6151 .1158 (cit. on p.5).

[2] Richard B Setlow. "The hazards of space travel”. In: EMBO reports 4.11 (2003), pp. 1013-1016. DoI: 10 . 1038/s j . embor . 7400016 (cit. on p. 5).

[3] K. F. Long. Deep Space Propulsion: A Roadmap to Interstellar Flight. New York: Springer, 2011. ISBN: 978-1-4614-0606-8 (cit. on p.5).

[4] Carl Sagan. Pale Blue Dot: A Vision of the Human Future in Space. New York: Ballantine Books, 1997. ISBN: 978-0-345-37659-6 (cit. on p. 5).

[5] Margaret Kohn and Kavita Reddy. "Colonialism”. In: The Stanford Encyclopedia of Philosophy. Ed. by Edward N. Zalta. Metaphysics Research Lab, Stanford University, 2017 (cit. on p. 5).

[6] Gary P. Latham. "The motivational benefits of goal-setting”. In: Academy of Management Perspectives 18.4 (2004), pp. 126-129. DoI: 10 . 5465/ame . 2 004.15268727 (cit. on p.6).

[7] Marko Kovic. Why does nobody care about existential risks? 2017 (cit. on p. 6.

[8] Catharine A. Conley. "Outer Space Treaty". In: Encyclopedia of Astrobiology. Springer, Berlin, Heidelberg, 2014, pp. 1-1. Dor: 10 . 1007 /978-3-64 2-27833-4_1132-2 (cit. on p.7).

[9] Francis Lyall and Paul B. Larsen. Space Law: A Treatise 2nd Edition. Abingdon, Oxon ; New York, NY: Routledge, 2017. IsBN: 978-1-4724-4782-1 (cit. on p. 7).

[10] Kenneth Chang. "If No One Owns the Moon, Can Anyone Make Money Up There?" In: The New York Times (2017) (cit. on p. 7).

[11] Hamilton DeSaussure. "Maritime and Space Law - Comparisons and Contrasts (An Oceanic View of Space Transport)”. In: Journal of Space Law 9 (1981), p. 93 (cit. on p. 7).

[12] Garrett Hardin. “The Tragedy of the Commons”. In: Science 162.3859 (1968), pp. 1243-1248. DOI: $10.1126 /$ science.162.3859.1243 (cit. on p. 8).

[13] Peng Wang. Tragedy of Commons in Outer Space - The Case of Space Debris. SSRN Scholarly Paper ID 2260856. Rochester, NY: Social Science Research Network, 2013 (cit. on p. 8). 
[14] Hao Liu and Fabio Tronchetti. "The American Space Commerce Free Enterprise Act of 2017: The latest step in regulating the space resources utilization industry or something more?" In: Space Policy (2018). Dor: 10 $.1016 /$ j.spacepol.2018.02.004 (cit. on p. 8).

[15] Gennady M. Danilenko. "International law-making for outer space”. In: Space Policy. Tribute to Frances Brown from Jill Stuart, Space Policy current Editor-in-Chief 37 (2016), pp. 179-183. Dor: 10 . 1016/j . spacepol . 2 016.12 .002 (cit. on p.8).

[16] Lawrence J. DeLucas. "International space station”. In: Acta Astronautica. Benefits of Space for Humanity 38.4 (1996), pp. 613-619. Dor: 10 . 1016 /0094-5765(96)00056-2 (cit. on p.8).

[17] Rochus Moenter. "The International Space Station: Legal Framework and Current Status”. In: Journal of Air Law and Commerce 64 (1998), p. 1033 (cit. on p. 8).

[18] M. F. Kozlovskaya Reschke. "Field Test: Results from the One Year Mission". In: Galveston, TX, United States, 2017 (cit. on p. 9).

[19] K. A. Binsted, M. Basner, W. Bedwell, Bryan Caldwell, D. Chang, J. Hunter, S. Kozlowski, J. Nasrini, P. Roma, J. Santoro, M. Seibert, B. Shiro, and P. Wu. "Investigations At Hi-SEAS into Team Function and Performance on Long Duration Exploration Missions”. In: 2016 (cit. on p. 9).

[20] Geoffrey Landis. "Terraforming Venus: A Challenging Project for Future Colonization”. In: AIAA SPACE 2011 Conference \& Exposition. AIAA SPACE Forum. American Institute of Aeronautics and Astronautics, 2011. DOI: 10.2514/6.2011-7215 (cit. on p.9).

[21] Sara Bruhns and Jacob Haqq-Misra. "A pragmatic approach to sovereignty on Mars”. In: Space Policy 38 (2016), pp. 57-63. DoI: 10 . $1016 / \mathrm{j}$ spacepol.2016.05.008 (cit. on p.9).

[22] Jacob Haqq-Misra. "The transformative value of liberating Mars". In: New Space 4.2 (2016), pp. 64-67. DoI: 10 . 1089/space. 2015.0030 (cit. on $\mathrm{p} .10$.

[23] Robert E. Hudec. "The New WTO Dispute Settlement Procedure: An Overview of the First Three Years". In: Minnesota fournal of Global Trade 8 (1999), p. 1 (cit. on p. 11).

[24] Paul Ingram, Jeffrey Robinson, and Marc L. Busch. "The Intergovernmental Network of World Trade: IGO Connectedness, Governance, and Embeddedness". In: American fournal of Sociology 111.3 (2005), pp. 824-858. DOI: $10.1086 / 497350$ (cit. on p. 12). 
[25] Sara McLaughlin Mitchell and Paul R. Hensel. "International Institutions and Compliance with Agreements". In: American fournal of Political Science 51.4 (2007), pp. 721-737. DOI: $10.1111 /$ j.1540-5907 .2007 .002 77 . $\mathrm{x}$ (cit. on p. 12).

[26] Jeremy Matam Farrall. United Nations Sanctions and the Rule of Law. Cambridge University Press, 2007. ISBN: 978-1-139-46851-0 (cit. on p.12).

[27] Marko Kovic, Adrian Rauchfleisch, and Christian Caspar. "Killing death: Some implications of extending human lifespan indefinitely". In: SocArXiv (2018). DOI: 10 . 17605/OSF . IO/ZSRU4 (cit. on p. 13).

[28] Derek Parfit. Reasons and Persons. Oxford: Oxford University Press, 1986. ISBN: 978-0-19-824908-5 (cit. on p. 13).

[29] David Benatar. Better Never to Have Been: The Harm of Coming into Existence. Oxford: Oxford University Press, 2008. ISBN: 978-0-19-954926-9 (cit. on p. 14.

[30] Thomas A. DiPrete and Gregory M. Eirich. "Cumulative Advantage as a Mechanism for Inequality: A Review of Theoretical and Empirical Developments". In: Annual Review of Sociology 32.1 (2006), pp. 271-297. DOI: 10.1146/annurev.soc. 32.061604 .123127 (cit. on p. 14.

[31] Thomas Piketty. "About Capital in the Twenty-First Century". In: American Economic Review 105.5 (2015), pp. 48-53. Dor: 10 . 1257 / aer.p20151 060 (cit. on p.15).

[32] Stephen Webb. If the Universe Is Teeming with Aliens ... WHERE IS EVERYBODY?: Fifty Solutions to the Fermi Paradox and the Problem of Extraterrestrial Life. Springer Science \& Business Media, 2002. ISBN: 978-0-387-95501-8 (cit. on p. 15).

[33] Charles S. Cockell. “The rights of microbes”. In: Interdisciplinary Science Reviews 29.2 (2004), pp. 141-150. DOI: $10.1179 / 030801804225012$ 635 (cit. on p. 16).

[34] Margaret S. Race and Richard O. Randolph. "The need for operating guidelines and a decision making framework applicable to the discovery of non-intelligent extraterrestrial life". In: Advances in Space Research 30.6 (2002), pp. 1583-1591. DOI: 10 . 1016/S0273-1177 (02) 00478-7 (cit. on p. 16).

[35] Erik Persson. "The Moral Status of Extraterrestrial Life”. In: Astrobiology 12.10 (2012), pp. 976-984. Dor: 10 . 1089 / ast . 2011.0787 (cit. on p. 16. 
[36] Charles S. Cockell. "The Ethical Status of Microbial Life on Earth and Elsewhere: In Defence of Intrinsic Value”. In: The Ethics of Space Exploration. Space and Society. Springer, Cham, 2016, pp. 167-179. ISBN: 978-3-31939825-9. DOI: 10 . $1007 / 978-3-319-39827-3 \_12$ (cit. on p. 16).

[37] Kelly C. Smith. "The Curious Case of the Martian Microbes: Mariomania, Intrinsic Value and the Prime Directive". In: The Ethics of Space Exploration. Space and Society. Springer, Cham, 2016, pp. 195-208. ISBN: 978-3-31939825-9. DOI: 10 . $1007 / 978-3-319-39827-3 \_14$ (cit. on p. 16).

[38] Ian J. H. Duncan. "The changing concept of animal sentience”. In: Applied Animal Behaviour Science 100.1 (2006), pp. 11-19. DOI: 10 . 1016 / j applanim.2006.04.011 (cit. on p.16).

[39] Thomas Nagel. “What Is It Like to Be a Bat?" In: The Philosophical Review 83.4 (1974), pp. 435-450. DOI: $10.2307 / 2183914$ (cit. on p. 16).

[40] Robert C. Jones. "Science, sentience, and animal welfare". In: Biology \& Philosophy 28.1 (2013), pp. 1-30. DOI: 10 . 1007/s10539-012-9351 - 1 (cit. on p. 16).

[41] Marko Kovic. Humankind will soon become a post-agricultural civilization. 2017 (cit. on p. 17).

[42] John A. Ball. "The zoo hypothesis”. In: Icarus 19.3 (1973), pp. 347-349. Dor: 10.1016/0019-1035(73)90111-5 (cit. on p. 17).

[43] Michael Noah Mautner. Seeding the Universe with Life: Securing Our Cosmological Future. Christchurch, N.Z.: Legacy Books, 2000. IsBN: 978-0-47600330-9 (cit. on p. 18).

[44] Brian Tomasik. Risks of Astronomical Future Suffering. 2015 (cit. on p. 18).

[45] Joshua S. Goldstein. Winning the War on War: The Decline of Armed Conflict Worldwide. Penguin, 2011. ISBN: 978-1-101-54908-7 (cit. on p. 19).

[46] Steven Pinker. The Better Angels of Our Nature: Why Violence Has Declined. New York Toronto London: Penguin Books, 2012. ISBN: 978-0-14-312201-2 (cit. on p. 19).

[47] Max Roser. War and Peace. 2018 (cit. on p. 19).

[48] “The growing danger of great-power conflict”. In: The Economist (2018) (cit. on p. 19).

[49] Miles Hewstone, Mark Rubin, and Hazel Willis. "Intergroup Bias”. In: Annual Review of Psychology 53.1 (2002), pp. 575-604. DOI: 10 . 1146 /annurev.psych.53.100901.135109 (cit. on p. 19). 
[50] Nick Haslam and Steve Loughnan. "Dehumanization and Infrahumanization”. In: Annual Review of Psychology 65.1 (2014), pp. 399-423. Dor: 10 . 1 146/annurev-psych-010213-115045 (cit. on p. 19).

[51] Phil Torres. "Space colonization and suffering risks: Reassessing the "maxipok rule"”. In: Futures 100 (2018), pp. 74-85. Dor: 10 . 1016/ j . futures . 2018.04 .008 (cit. on p. 19).

[52] Nick Bostrom. Superintelligence: Paths, Dangers, Strategies. Oxford, United Kingdom ; New York, NY: Oxford University Press, 2016. ISBN: 978-0-19873983-8 (cit. on p. 20).

[53] Marko Kovic. "METI (Messaging Extra Terrestrial Intelligence) is irrational and should be abandoned". In: SocArXiv (2017). DOI: 10 . 17605/OSF IO/CR479 (cit. on p. 20).

[54] Marko Kovic. The future of humankind will be determined by policy. 2018 (cit. on p. 21). 